\title{
Growth of Nanodendrites on Insulator Substrates by Charge-up Induced Deposition and its Decoration with Metal Nanocrystals
}

\author{
Kazuo Furuya, Guoqiang Xie and Minghui Song \\ High Voltage Electron Microscopy Station, National Institute for Materials Science, Tsukuba 305- \\ 0003, Japan
}

The fractal growth of nano-tree-like structures has been attracting materials scientists because of the functionality of structures with very large areas of the surface. We have been investigating the behavior of metal nanostructures growth on insulator substrates under electron irradiation [1-4]. The surface of insulating samples in the transmission electron microscopes (TEM) is always electrically charged up under the observation. The inhomogeneous distribution of electron flux enhances the decomposition of residual gases in the chamber. When metal precursor gases are flowed on the surfaces, inhomogeneous deposition and growth of metal nanostructures result in the formation of "nano-wires", "nano-dendrites" and "nano-trees".

In the present study, nanometer-sized $\mathrm{W}$-dendrite structures were firstly grown on $\mathrm{Al}_{2} \mathrm{O}_{3}$ and $\mathrm{SiO}_{2}$ substrates using a charge-up induced deposition (CID) process in TEMs operated at $200-1000 \mathrm{kV}$. The morphology of the structures was examined as a function of electron current density. Sequentially, Au nanoparticles were deposited on the W-nanodendrites using ion sputtering method and formed a compound Au-nanoparticles/W-nanodendrite structure. The as-fabricated structures were characterized by the combination of TEM and energy dispersive X-ray spectroscopy (EDS).

Fig. 1 shows three different morphologies of $\mathrm{W}$-dendrite structures with various electron current densities [5]. At about $0.75 \mathrm{~A} / \mathrm{cm}^{2}$, the deposits grew self-standing at positions separated each other and nearly perpendicular to surface of the substrate. Thickness of these wires is about $3 \mathrm{~nm}$ and in length of several nanometers. When the current density was increased to about $3.2 \mathrm{~A} / \mathrm{cm}^{2}$, the dendrites only grew at edge of the substrate with convex surface in the irradiated area. The thickness of the dendrites becomes thicker with the place going near the substrate, but is about $3 \mathrm{~nm}$ at tips. Branches are observed at the tip. It becomes a fractal-like tree structure grown at a current density of about $17.9 \mathrm{~A} / \mathrm{cm}^{2}$.

To obtained the structures decorated by Au-nanoparticles, the sputtering experiments were carried out ex-situ. Fig. 2 shows a TEM micrograph of the as-fabricated Au-nanoparticle/W-nanodendrite compound structure on an $\mathrm{Al}_{2} \mathrm{O}_{3}$ substrate for an ion sputtering time of $7 \mathrm{~s}$. It is seen that the nanoparticles are almost uniformly distributed on the $\mathrm{W}$-nanodendrites. Distribution density of the Au-nanoparticles based on measuring 10 regions of $50 \mathrm{~nm} \times 50 \mathrm{~nm}$ is $2.74 \times 10^{12} \mathrm{~cm}^{-2}$. HRTEM images in Fig. 2-b) revealed the formation of nanocrystals, which have several different lattice fringes. The lattice fringe in some regions is $0.22 \mathrm{~nm}$ which is close to the lattice spacing of 0.224 $\mathrm{nm}$ for $\{110\}$ of bcc-W, while that in other region is measured to be $0.24 \mathrm{~nm}$ which is close to the lattice spacing of $0.236 \mathrm{~nm}$ for $\{111\}$ of fcc-Au. This result encouraged to easy distiguishment between $\mathrm{W}$ and $\mathrm{Au}$ nanostructures. Fig. 3-a) shows an EDS spectrum taken at the tips of the asfabricated Au-nanoparticle/W-nanodendrite compound structures. It is indicated that the peaks of $\mathrm{Au}$ and $\mathrm{W}$ dominate the spectrum although there are small amounts of $\mathrm{C}$ and $\mathrm{O}$, as shown in Fig. 3a). Fig. 3-b) gives the measured results of the grain size distribution of Au nanoparticles based on measuring 207 grain diameters. It is seen that there is a relatively narrow grain size distribution. The average grain size at the present ion sputtering conditions is $2.1 \mathrm{~nm}$. The grain size can be easily controlled by controlling the ion sputtering time.

\section{References}

[1] M. Song, K. Mitsuishi, M. Takeguchi and K. Furuya, Appl. Surf. Sci., 241 (2005) 107.

[2] G. Xie, M. Song, K. Mitsuishi and K. Furuya: J. Nanosci., Nanotech., 5 (2005) 615.

[3] G. Xie, M. Song, K. Mitsuishi and K. Furuya: Physica E, 29 (2005) 564 
[4] G. Xie, M. Song, K. Mitsuishi and K. Furuya: J. J. Appl. Phys., 44 (2005) 5654

[5] M. Song, K. Mitsuishi, M. Tanaka, M. Takeguchi, M. Shimojo and K. Furuya, Appl. Phys. A, $80(2005) 1431$.
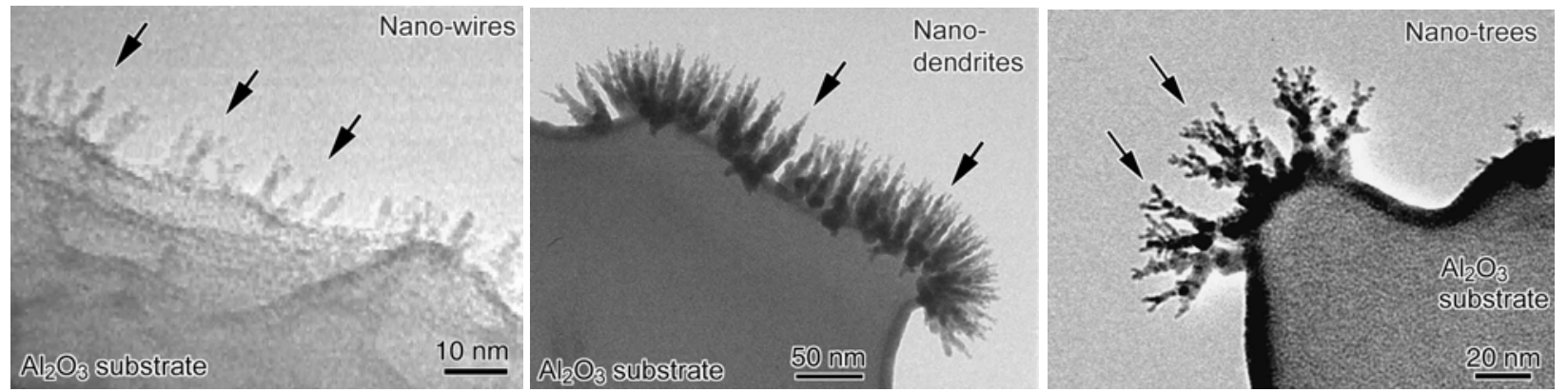

Fig.1 W-nanostructure growth on $\mathrm{Al}_{2} \mathrm{O}_{3}$ substrate under various electron current densities at room temperature. a) Nano-wires with $0.75 \mathrm{~A} / \mathrm{cm}^{2}$, b) Nano-dendrites with $3.2 \mathrm{~A} / \mathrm{cm}^{2}$ and c) Nano-trees with $17.9 \mathrm{~A} / \mathrm{cm}^{2}$.
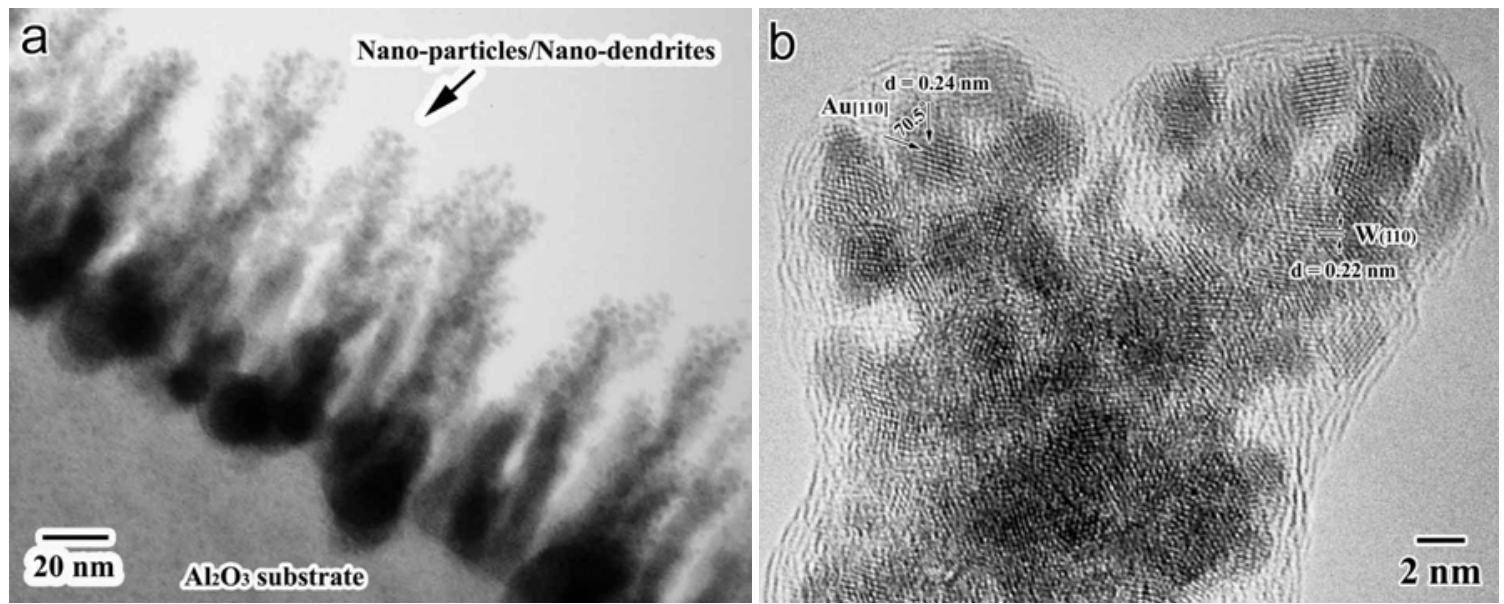

Fig.2 TEM images of compound structure of Au-nano-particles/W-nano-dendrites after the growth and deposition at room temperature. (a) Low magnification and (b) HREM image.
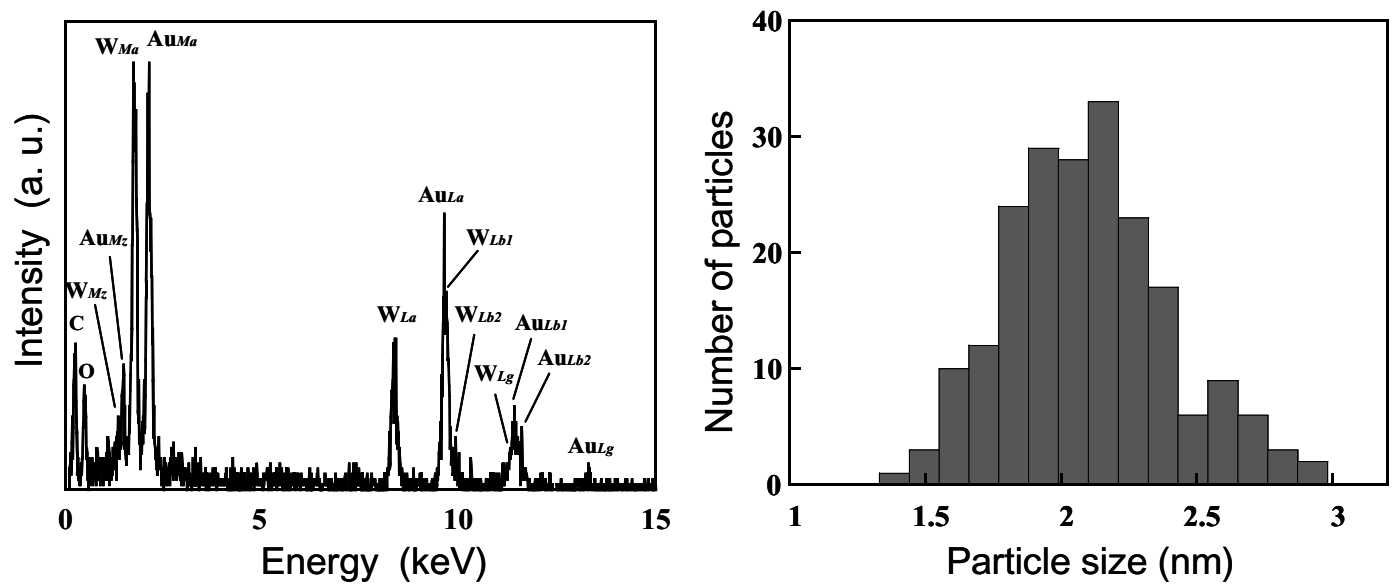

Fig. 3 EDS results of the compound of Au-particles/W-nano-dendrites and the size distribution of Au-particles deposited on the nano-dendrites. 